\title{
Comparative evaluation of test characteristics of acetic acid, lugol's iodine and toluidine blue stains in cervical cancer screening
}

\author{
Ankita Kumari $^{1 *}$, Neha Singh ${ }^{1}$, Shaila Mitra ${ }^{2}$, Reena Srivastav ${ }^{1}$
}

\begin{abstract}
${ }^{1}$ Department of Obstetrics and Gynecology, ${ }^{2}$ Department of Pathology, BRD Medical College, Gorakhpur, Uttar
\end{abstract} Pradesh, India

Received: 16 September 2017

Accepted: 22 September 2017

*Correspondence:
Dr. Ankita Kumari,
E-mail: drankita09@gmail.com

Copyright: () the author(s), publisher and licensee Medip Academy. This is an open-access article distributed under the terms of the Creative Commons Attribution Non-Commercial License, which permits unrestricted non-commercial use, distribution, and reproduction in any medium, provided the original work is properly cited.

\begin{abstract}
Background: Cervical cancer rank second in female cancer and India alone account for one fourth of the global cervical cancer burden. The study was aimed to evaluate the diagnostic efficacy of acetic acid (3\%), lugol's iodine and toluidine blue (1\%) in detection of abnormal cervical lesions.

Methods: This cross-sectional study was conducted in the Department of Obstetrics and Gynecology, BRD Medical College, Gorakhpur over a period of one year from July 2016 to June 2017. The study included 200 women in age group 20-60 years with signs and symptoms suspicious of abnormal cervical lesion. The cases were subjected to detailed history, clinical examination, Pap smear, Visual inspection test, colposcopy followed by cervical biopsy.

Results: Out of total 200 patients, 114 patients had acetowhite area on VIA (visual inspection with acetic acid) test, 113 were VILI (visual inspection with lugol's iodine) positive and 107 women stained positive with Toluidine blue but only 88 showed biopsy proven pre-invasive and invasive lesions. So, sensitivity of acetic acid, lugol's iodine and Toluidine blue was $81.8 \%, 84.09 \%$ and $90.9 \%$ respectively. Similarly, the specificity of the three stains were $62.5 \%$, $65.17 \%$ and $75.8 \%$ respectively.

Conclusions: Toluidine blue (1\%) has proved to be significantly more sensitive and specific stain as compared to acetic acid (3\%) and lugol's iodine (50\% dilution) in diagnosing pre-invasive and invasive cervical cancer. Hence, it may aid as an important tool in screening and treating precancerous and cancerous lesions.
\end{abstract}

Keywords: Abnormal cervical lesions, Colposcopy, Invasive cervical cancer, Precancerous lesions, Visual inspection test

\section{INTRODUCTION}

Cervical cancer rank second in female cancer and India alone account for one fourth of the global cervical cancer burden. About 122,844 new cervical cancer cases are diagnosed annually in India and 67,477 die from it. ${ }^{1}$ Mortality due cervical cancer is also an indicator of health inequities, as $86 \%$ of all deaths due to cervical cancer are in developing, low and middle income countries. $^{2-4}$ Invasive cervical cancer is preceded by a long phase of precancerous lesion that can be detected by screening and if treated can prevent the invasive cancers. Despite careful examination, small developing lesions often go unrecognized by clinicians. To aid visual inspection in addition to normal light wide range of commercial adjunctive aids are available. All these adjunctive aids will of great use in detecting small lesion with a certain amount of dysplasia which appears normal under routine visual inspection.

Cytology based screening programmes are difficult to organize owing to limited infrastructure, trained personnel and funds. ${ }^{5}$ Thus, in developing countries like ours, there is need for alternative strategies which are available on large scale, cost effective and easy. 
Prompted by the need for optimal strategies for cervical cancer screening in low resource settings, the role of visual inspection with acetic acid (VIA) and visual inspection with lugol's iodine (VILI) has been widely studied in several recent studies which suggest that VIA and VILI closely match the Pap smear in its performance in detecting cervical cancer precursor. ${ }^{6}$

Acetic acid and lugol's iodine are cytoplasmic stains in which nuclear activity may be missed. Toluidine blue (also known as tolonium chloride) is a vital metachromatic dye of thiazine group, having selective nuclear staining property and may aid in diagnosing preinvasive and invasive cervical lesion with more sensitivity and specificity. Toluidine blue (TB) stains dysplastic and anaplastic cells because of the increase in their nuclear content when compared to normal tissue. ${ }^{7}$ Although enormous literature has been available on the several adjunctive tools like acetic acid and Lugol's iodine but the role of Toluidine blue on cervical lesions are limited and their effectiveness remains a question mark till now. With this view, the current study was conducted to evaluate the diagnostic efficacy of acetic acid (3\%), lugol's iodine (50\% dilution) and toluidine blue $(1 \%)$ in preinvasive and invasive cervical cancer lesions.

\section{METHODS}

The present cross-sectional study was conducted in Department of Obstetrics and Gynecology, BRD Medical College, Gorakhpur from July 2016 to June 2017. The study included 200 women in the age group of 20-60 years presenting with complaints of persistent vaginal discharge, intermenstrual bleeding, post coital bleeding or with an unhealthy cervix on examination.

Table 1: IARC Criteria for interpretation of VIA and VILI.

\begin{tabular}{|c|c|}
\hline \multicolumn{2}{|c|}{ IARC Criteria } \\
\hline $\begin{array}{l}\text { VIA } \\
\text { positive }\end{array}$ & $\begin{array}{l}\text { - Well defined, sharp, distinct, dense acetowhite areas with or without raised margins, abutting the } \\
\text { squamo-columnar junction in the transformation zone } \\
\text { - Strikingly dense acetowhite area in the columnar epithelium } \\
\text { - Condyloma and leukoplakia occurring closer to the squamo-columnar junction turning intensely } \\
\text { white after application of acetic acid }\end{array}$ \\
\hline $\begin{array}{l}\text { VIA } \\
\text { negative }\end{array}$ & $\begin{array}{l}\text { - No acetowhite lesions on the cervix } \\
\text { - Polyps protruding from the cervix with bluish-white acetowhite areas } \\
\text { - Nabothian cysts appearing as button like areas/whitish acne, or pimples } \\
\text { - Faint line-like or ill-defined acetowhitening at squamocolumnar junction } \\
\text { - Shiny, pinkish-white, cloudy-white, bluish-white, faint patchy, or doubtful lesions with ill-defined, } \\
\text { indefinite margins, blending with the rest of the cervix } \\
\text { - Angular, irregular, digitating, acetowhite lesions resembling geographical regions, far away from the } \\
\text { - Iransformation zone (satellite lesions) } \\
\text { - } \text { and mucopurulent discharge } \\
\text { - Red spots on cervix against pinkish-white background after applying acetic acid } \\
\text { - Streak-like acetowhitening in the columnar epithelium } \\
\text { Dot-like areas in the endocervix, which are due to grape-like columnar epithelium staining with acetic } \\
\text { acid }\end{array}$ \\
\hline $\begin{array}{l}\text { VILI } \\
\text { positive }\end{array}$ & $\begin{array}{l}\text { Dense, thick, bright, mustard-yellow or saffron yellow iodine non-uptake areas abutting the squamo- } \\
\text { columnar junction in the transformation zone }\end{array}$ \\
\hline $\begin{array}{l}\text { VILI } \\
\text { negative }\end{array}$ & $\begin{array}{l}\text { - Normal cervix where squamous epithelium turns mahogany brown or black and the columnar } \\
\text { epithelium does not change colour; no yellow area seen } \\
\text { - In ectropion, when an extensive area of columnar epithelium with regular margins on the ectocervix } \\
\text { remains without colour change } \\
\text { - Patchy, indistinct, ill-defined, colourless or partially brown areas are seen in the cervix } \\
\text { - Non or partial-iodine uptake, pale areas corresponding to pre-existing nabothian follicles and/or } \\
\text { polyps are seen } \\
\text { - Stippling or leopard skin appearance associated with T. vaginalis infection } \\
\text { - When pepper-like non-iodine uptake areas seen in the squamous epithelium far away from the } \\
\text { - } \text { - When samo-columnar junction } \\
\text { geographical areas are seen far away from the squamo-columnar junction }\end{array}$ \\
\hline
\end{tabular}


Women <20 years and >60 years of age, unmarried, pregnant women, women having active infection or bleeding per vaginum, women with frank cervical growth, prior hysterectomy or treatment for cervical precancer or cancer were excluded from the study. After taking informed consent, the cases were subjected to detailed history, general, physical and per speculum examination.

Each patient underwent Pap smear, visual inspection test with acetic acid (3\%), lugol's iodine, toluidine blue (1\%), colposcopy followed by cervical biopsy. VIA was carried out by applying $3 \%$ freshly prepared acetic acid on cervix and read after 2 minutes. After VIA, VILI was done by applying lugol's iodine over ectocervix (prepared by dissolving $5 \mathrm{gm}$ of iodine and $10 \mathrm{gm}$ of potassium iodide in $100 \mathrm{ml}$ of distilled water), waited for 2 minutes and examined thoroughly. Results of VIA and VILI were interpreted using the criteria laid down by IARC (Table $1)$.

On the next day subjects were called for toluidine blue test which was done by applying $1 \%$ TB over ectocervix for 2 minutes. Results were interpreted as test positive when lesion stained blue and test negative when blue area was absent. The study was approved by institutional ethical committee.

\section{Statistical analysis}

After analyzing data by Fisher's exact test, results were compared between the three stains. For all statistical purposes, $\mathrm{p}$ value $<0.05$ was considered significant. Using histological diagnosis as gold standard, the sensitivity, specificity, positive predictive value and negative predictive value of VIA, VILI and TB were calculated separately.

\section{RESULTS}

Most of the women $(60 \%)$ in the present study were in age group of 30-39 years with the mean age of $36 \pm 4.5$ years (Table 2).

Majority of them (55\%) were multiparous. $64.5 \%$ women had no formal education whereas $23.5 \%$ had some primary education and $12 \%$ received education upto high school or above. $65 \%$ of women belonged to rural area while $35 \%$ resided in urban area. Most women $(89.5 \%)$ screened were Hindu and the rest were Muslim and others communities.

Majority of women belonged to lower (61\%) and middle $(36 \%)$ socioeconomic classes. Mean age of marriage was $18.8 \pm 2.6$ years while mean age at first coitus was $18.1 \pm 2.2$ yrs.

Six percent of women were having multiple sexual partners and $21 \%$ had history of recurrent sexually transmitted infections. Five percent of women were smokers.

Table 2: Demographic profile of patients.

\begin{tabular}{|c|c|c|c|}
\hline Variables & & Number & $\%$ \\
\hline \multirow{4}{*}{ Age (years) } & $20-29$ & 22 & 11 \\
\hline & $30-39$ & 120 & 60 \\
\hline & $40-49$ & 41 & 21 \\
\hline & $50-59$ & 17 & 8.5 \\
\hline \multirow{3}{*}{ Parity } & Nulliparous & 20 & 10 \\
\hline & Primi & 70 & 35 \\
\hline & Multi & 110 & 55 \\
\hline \multirow{3}{*}{ Education } & Illiterate & 129 & 64.5 \\
\hline & Primary & 47 & 23.5 \\
\hline & $\begin{array}{l}\text { High school } \\
\text { and above }\end{array}$ & 24 & 12 \\
\hline \multirow{2}{*}{ Habitant } & Rural & 130 & 65 \\
\hline & Urban & 70 & 35 \\
\hline \multirow{3}{*}{ Religion } & Hindu & 179 & 89.5 \\
\hline & Muslim & 18 & 9 \\
\hline & Other & 3 & 1.5 \\
\hline \multirow{3}{*}{$\begin{array}{l}\text { Socioeconomic } \\
\text { status }\end{array}$} & High & 6 & 3 \\
\hline & Middle & 72 & 36 \\
\hline & Low & 122 & 61 \\
\hline \multirow{2}{*}{ Smoking } & Yes & 10 & 5 \\
\hline & No & 190 & 95 \\
\hline \multirow{2}{*}{$\begin{array}{l}\text { Multiple sexual } \\
\text { partners }\end{array}$} & Yes & 12 & 6 \\
\hline & No & 188 & 94 \\
\hline \multirow{3}{*}{$\begin{array}{l}\text { Age at marriage } \\
\text { (yrs) }\end{array}$} & $15-20$ & 178 & 89 \\
\hline & $21-25$ & 16 & 8 \\
\hline & $26-30$ & 6 & 3 \\
\hline \multirow{3}{*}{$\begin{array}{l}\text { Age at first } \\
\text { coitus (yrs) }\end{array}$} & $15-20$ & 182 & 91 \\
\hline & $21-25$ & 14 & 7 \\
\hline & $26-30$ & 4 & 2 \\
\hline \multirow{2}{*}{$\begin{array}{l}\text { Recurrent } \\
\text { STI/RTI }\end{array}$} & Yes & 42 & 21 \\
\hline & No & 158 & 79 \\
\hline
\end{tabular}

Vaginal discharge (39\%) was the most common symptom followed by pain in abdomen $(30 \%)$ and postmenopausal bleeding (18\%) (Figure 1).

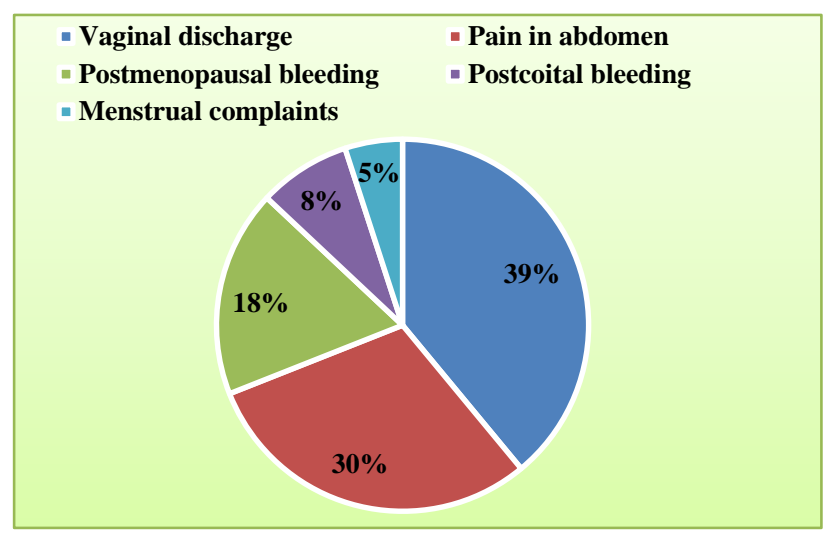

Figure 1: Distribution of subjects according to symptoms. 


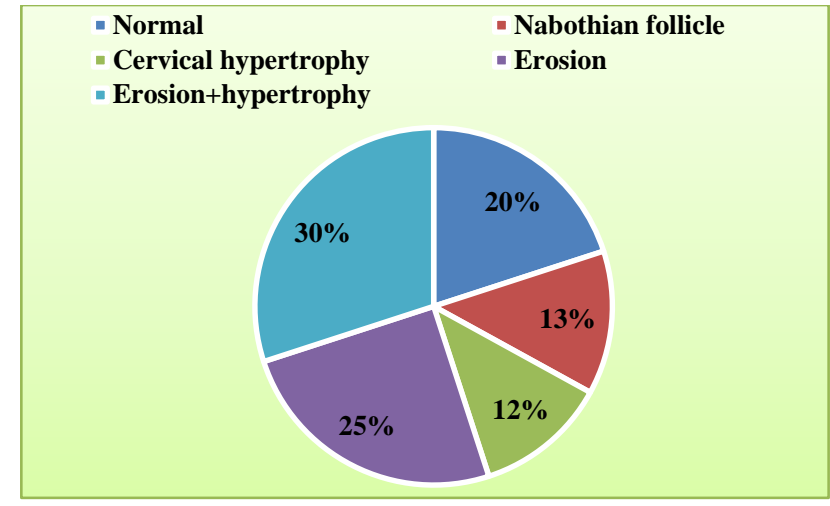

Figure 2: Distribution of patients according to per speculum findings.

The commonest finding on per speculum examination was cervical hypertrophy with erosion (Figure 2). Pap smear was normal in $17 \%$ of women, low grade squamous intraepithelial lesion (LSIL) was found in $26 \%$, high grade squamous intraepithelial lesion (HSIL) in
$14.5 \%$ and findings suspicious of carcinoma cervix were seen in $2 \%$ of women (Table 3 ).

Table 3: Distribution of subjects according to Pap smear findings (Bethesda System).

\begin{tabular}{|lll|}
\hline Pap smear findings & Number & $\%$ \\
\hline Normal & 34 & 17 \\
\hline Inflammatory & 45 & 22.5 \\
\hline Koilocytes & 10 & 5 \\
\hline Reparative & 8 & 4 \\
\hline ASCUS & 18 & 9 \\
\hline LSIL & 52 & 26 \\
\hline HSIL & 29 & 14.5 \\
\hline Carcinoma & 4 & 2 \\
\hline
\end{tabular}

Out of 200 patients, 114 patients had acetowhite area on VIA test (57\%), 113 were VILI positive (56.5\%) and 107 women stained positive with Toluidine blue $(53.5 \%)$ but only $88(44 \%)$ showed biopsy proven preinvasive and invasive lesions (Table 4).

Table 4: Comparison of visual inspection test.

\begin{tabular}{|c|c|c|c|c|c|c|c|c|}
\hline \multirow{2}{*}{ Test } & \multicolumn{2}{|l|}{ VIA } & \multicolumn{2}{|c|}{ VILI } & \multicolumn{2}{|c|}{ Toluidine blue } & \multicolumn{2}{|c|}{ Biopsy } \\
\hline & No. & $\%$ & No. & $\%$ & No. & $\%$ & No. & $\%$ \\
\hline Positive & 114 & 57 & 113 & 56.5 & 107 & 53.5 & 88 & 44 \\
\hline Negative & 86 & 43 & 87 & 43.5 & 93 & 46.5 & 112 & 56 \\
\hline Fisher's exact ( $\mathrm{p}$ value) & 0.0213 & & 0.02 & & 0.10 & & & \\
\hline
\end{tabular}

Table 5: Distribution of patients according to Colposcopic-directed biopsy.

\begin{tabular}{|lll|}
\hline Biopsy findings & Number & Percent \\
\hline Normal & 40 & 20 \\
\hline Chronic cervicitis & 72 & 36 \\
\hline CIN-1 & 49 & 24.5 \\
\hline CIN-2 & 22 & 11 \\
\hline CIN-3 & 08 & 4 \\
\hline Carcinoma in situ & 05 & 2.5 \\
\hline Carcinoma & 04 & 2 \\
\hline Total & 200 & 100 \\
\hline
\end{tabular}

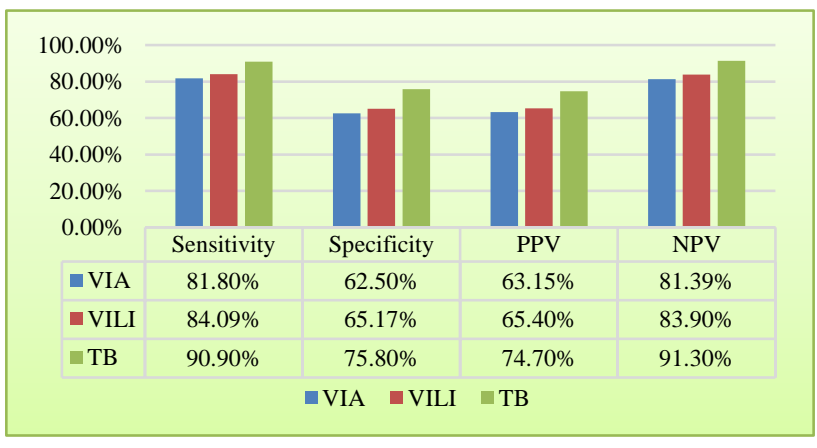

Table 6: Comparison of three stains.
On colposcopic guided biopsy, 20\% had normal findings, $36 \%$ had chronic cervicitis, $24.5 \%$ had CIN I, $11 \%$ had CIN-II, $4 \%$ had CIN-III, $2.5 \%$ showed carcinoma in situ and $2 \%$ had invasive cervical carcinoma (Table 5). So, sensitivity of acetic acid, lugol's iodine and toluidine blue was $81.8 \%, 84.09 \%$ and $90.9 \%$ respectively. The specificity of the three stains were $62.5 \%, 63.17 \%$ and $75.8 \%$ (Figure 3).

\section{DISCUSSION}

Majority of cases of cervical cancer are diagnosed at an advanced stage as cytology based screening programmes are ineffective in developing countries. If detected and treated timely, pre-invasive disease has nearly 100 percent survival rates. ${ }^{8}$ VIA, VILI are well established alternate approaches to cervical cytology in low resource settings. However, nuclear stains like Toluidine blue had limited reports of being used in vivo in the cervix or vagina. So, the current study was undertaken to compare the test characteristics of the three available staining modalities in detection of abnormal cervical lesions.

In the present study, maximum women $(60 \%)$ were in the age group of 30-39 years. A large study done by Luthra et 
$\mathrm{al}^{9}$ revealed mean ages for mild, moderate and severe dysplasia to be $33.8,35.2$ and 40.2 years. Therefore, screening for cervical carcinoma should start ideally at the onset of sexual activity and all women should be screened at least once by the age of 30-35 years. The mean age of marriage among the study population was $18.8 \pm 2.6$ years while that of coitarche was $18.1 \pm 2.2$ years. These findings were comparable to the study performed by Bhatla et al where mean age at first coitus was $19 \pm 3.3$ years. ${ }^{10}$ The women in this study attained coitarche before marriage with early exposure to sex and indeed sexually transmitted infections like HPV which is a risk factor for cervical cancer. Moreover, early initiation of sex before marriage is more likely to result into having multiple sexual partners. This will lead to early initiation of cancerous changes in the cervix.

In the present series, the most common presenting symptom was persistent vaginal discharge (39\%) followed by pain in abdomen $(30 \%)$. On per speculum examination majority of women had erosion $(25 \%)$ and erosion with hypertrophy $(30 \%)$. Our findings were consistent with the findings of Satyanarayana et al. ${ }^{11}$

In various studies worldwide, there is relatively wide range of sensitivity, specificity and positive predictive value reported with Pap smear. Published sensitivity estimates for Pap smear have ranged from 11-99\% and specificity from $14-97 \% .{ }^{12}$ However, the sensitivity and specificity for conventional cytology in our study was $51.5 \%$ and $55 \%$ respectively. Pap smear has various limitations besides low sensitivity. These include the need for repeated visits for screening, collection of report, evaluation of abnormal results and treatment, and requirement for laboratory infrastructure, highly trained cytopathologists and staff for large scale screening. This hinders the use of Pap smear on a large scale in low resource settings. This has led to the need for alternate methods which are cheap, easy to perform, can be done by paramedical workers and give immediate results.

The sensitivity of acetic acid, lugol's iodine and toluidine blue were $81.8 \%, 84.09 \%$ and $90.9 \%$ respectively while the specificity of the three stains were $62.5 \%, 65.17 \%$ and $75.8 \%$ respectively. The results were in concordance with that of Sankaranarayan et al, who found that the sensitivity of VIA and VILI was $82 \%$ and $87 \%$ respectively and the specificity was $78 \%$ and $84 \%$ respectively. ${ }^{6,13}$ Epstein et al showed sensitivity and specificity of toluidine blue in premalignant oral squamous cancer as $92.5 \%$ and $63.2 \%$ respectively. ${ }^{14}$ In the current study the positive predictive value of VIA, VILI and TB was found to be $63.15 \%, 65.4 \%$ and $74.7 \%$ respectively whereas negative predictive value was $81.39 \%, 83.9 \%$ and $91.3 \%$ respectively. Singh et al in their study found that Toluidine blue was more sensitive $(70.83 \%)$ and specific $(88.46 \%)$ in detection of abnormal cervical lesions when compared to acetic acid $(58.3 \%$ and $87.5 \%)$ and lugol's iodine $(62.2 \%$ and $85.1 \%)$ with higher positive and negative predictive values. ${ }^{15}$

\section{CONCLUSION}

Toluidine blue (1\%) has proved to be more sensitive and specific stain as compared to acetic acid (3\%) and lugol's iodine in diagnosing pre-invasive and invasive cervical cancer. Hence, it may aid as potential alternative to the commonly used stains in screening precancerous and cancerous lesion of cervix. However, to establish the diagnostic accuracy of Toluidine blue, it should be studied in different concentrations and in larger populations.

Funding: No funding sources

Conflict of interest: None declared

Ethical approval: The study was approved by the Institutional Ethics Committee

\section{REFERENCES}

1. WHO, ICO information center on HPV and cervical cancer. Summary report Apr. 2017. Available at www.hpcenter.net.

2. Satija A. Cervical cancer in India. South Asia centre for chronic disease. Available at http://sancd.org/uploads/pdf/cervical_cancer.pdf. Accessed on February16, 2014.

3. Arbyn M, Castellsagué X, de Sanjosé S, Bruni L, Saraiya M, Bray F, Ferlay J. Worldwide burden of cervical cancer. Ann Oncol. 2011;22:2675-86.

4. Yeole BB, Kumar AV, Kurkureet A, Sunny L. Population-based survival from cancers of breast, cervix and ovary in women in Mumbai. Asian Pac J Cancer Prev. 2004;5:308-315.

5. Shastri SS, Dinshaw K, Amin G, Goswami S, PatilS, Chinoy R, et al. Concurrent evaluation of visual, cytological and HPV testing as screening methods for early detection of cervical neoplasia in Mumbai, India. Bull World Health Organ. 2005;83:186-94.

6. Sankanarayanan R, Wesley R, Thara S, Dhakad N, Chandralekha B, Sebastian $\mathrm{P}$ et al. Test characteristics of visual inspection with $4 \%$ acetic acid(VIA) and lugol's iodine(VILI) in cervical cancer screening in Kerela India. Int $\mathbf{J}$ Cancer 2003;106:404-8.

7. Martin IC, Kerawala CJ, Reed M. The application of toluidine blue as a diagnostic adjunct in the detection of epithelial dysplasia. Oral Surg Oral Med Oral Pathol Oral Radiol Endod. 1998;85:444-6.

8. Dinshaw KA, Shastri SS. Screening for cervical cancer in India. Natl Med J India. 2001;14:1-3.

9. Luthra UK, Prabhakar AK, Seth P, Agarwal SS, Murthy NS, Bhatnagar P, et al. Natural history of precancerous and early cancerous lesions of the uterine cervix. Acta Cytol. 1987;31:226-34.

10. Bhatla N, Mukhopadhyay A, Joshi S, Kumar A, Kriplani A, Pandey RM, et al. Visual inspection for cervical cancer screening: evaluation by doctor versus paramedical worker. Ind $\mathbf{J}$ Cancer. 2004;41(1):32-6. 
11. Satyanarayana L, Asthana S, Bhambani S, Sodhani P, Gupta S. A comparative study of cervical cancer screening methods in a rural community setting of North India. Indian J Cancer. 2014;51:124-8.

12. Fahey MT, Irwig L, Macaskill P. Meta-analysis of Pap test accuracy. Am J Epidemiol. 1995;141:680-9.

13. Sankarnarayanan R, Rajkumar R, Arrossi S, Theresa $\mathrm{R}$, Esmy PO, Mahé C, et al. Determinants of participation of women in a cervical cancer visual screening trial in rural south India. Cancer Detection Prev. 2003;27(6);457-65.

14. Epstien JB, Scully C, Spinelli J. Toluidine blue and Lugol's iodine application in assessment of oral malignant and lesion at risk of malignancy. J Oral Pathol Med. 1992;21(4):160-3.

15. Singh S, Chandra M, Singh R. Efficacy of three available staining modalities in diagnosing abnormal lesions of cervix. Asian J Obstet Gynecol Practice. 2011;3:18-20.

Cite this article as: Kumari A, Singh N, Mitra S, Srivastav R. Comparative evaluation of test characteristics of acetic acid, lugol's iodine and toluidine blue stains in cervical cancer screening. Int J Reprod Contracept Obstet Gynecol 2017;6:485762. 